\title{
REVISTA BRASILEIRA DE
} AGRICULTURA RRIGADA

Revista Brasileira de Agricultura Irrigada v.13, nº.6, p. 3731 - 3740, 2019

ISSN 1982-7679 (On-line)

Fortaleza, CE, INOVAGRI - http://www.inovagri.org.br

DOI: $10.7127 /$ rbai.v13n6001144

Protocolo 1144.19 - 18/04/2020 Aprovado em 11/05/2020

\section{TIPOS DE SUBSTRATOS NA GERMINAÇÃO E NO DESENVOLVIMENTO INICIAL DA PINHA}

Cicero Lima de Almeida ${ }^{1}$, Joilson Silva Lima ${ }^{2}$, James do Nascimento Costa ${ }^{3}$, Pedro Oliveira Filho ${ }^{3}$, Manoel Valnir Júnior ${ }^{4}$, Dimitri Matos Silva ${ }^{5}$

\section{RESUMO}

O objetivo deste trabalho foi avaliar a germinação e o desenvolvimento inicial da pinha (Annona squamosa L.), semeada em diferentes substratos. O experimento foi conduzido em telado agrícola (sombrite 50\%) pertencente ao Instituto Federal do Ceará/Campus Sobral, no período de outubro a dezembro de 2018. O delineamento experimental utilizado foi o inteiramente casualizado, com cinco tratamentos [T1 - fibra de coco (FC); T2 - fibra de coco + esterco caprino (FC + EC); T3 - esterco caprino (EC); T4 - esterco caprino + solo $(\mathrm{EC}+\mathrm{S})$; e T5 - solo (So)], com quatro repetições, sendo 32 sementes por repetição. Aos 50 dias após a semeadura foram avaliados o percentual de germinação $(\mathrm{G}, \%)$, a altura das plântulas $(\mathrm{H}, \mathrm{cm})$, o número de folhas (NF, unid), o diâmetro do caule (DC, mm), a massa fresca da parte aérea (MFA, g planta ${ }^{-1}$ ), a massa fresca total (MFT, $\mathrm{g}$ planta $^{-1}$ ), a massa seca da parte aérea (MSA, g planta ${ }^{-1}$ ), a massa seca total (MST, g planta ${ }^{-1}$ ), a porcentagem de massa seca (PMS, \%) e a porcentagem da massa da raiz na planta (PR, \%). O substrato composto por fibra de coco e esterco caprino (1:1), é o mais indicado para a produção de mudas de pinha, por proporcionar melhor desenvolvimento inicial associado à boa percentagem de germinação. O substrato composto apenas por solo retarda a germinação das plântulas e proporciona menor desempenho para o desenvolvimento inicial de mudas de pinha, sendo recomendado seu uso misturado com outros materiais.

Palavras-chave: Annona squamosa, semente, fibra de coco.

\footnotetext{
${ }^{1}$ Dr. Eng. Agrícola; IFCE - Campus Sobral, Av. Dr. Guarani, 317 - Derby Clube, Sobral - CE, 62042-030, e-mail: cicero.almeida@ifce.edu.br

${ }^{2}$ Dr. Fitotecnia; IFCE - Campus Sobral, e-mail: joilson.lima@ifce.edu.br

${ }^{3}$ Graduandos Tecnologia em Irrigação e Drenagem; IFCE - Campus Sobral, e-mail: jamesnascimento07@gmail.com; pedrooliveira1998.pfo@gmail.com

${ }^{4}$ Prof. Eixo Recursos Naturais; IFCE - Campus Sobral, e-mail: valnirjvm@yahoo.com.br

${ }^{5}$ Ms. Solos e Nutrição de Plantas; IFCE - Campus Sobral, e-mail: dimitri.silva@ifce.edu.br
} 


\title{
KINDS OF SUBSTRATES IN GERMINATION AND INITIAL DEVELOPMENT OF CUSTARD APPLE
}

\begin{abstract}
The objective of this work was evaluating the germination and the initial development of the custard apple (Annona squamosa L.) in different substrates. The experiment was carried out on an agricultural screen, belonging to the Instituto Federal do Ceará-IFCE/Campus Sobral, from October to December 2018. The experimental design used was completely randomized, with five treatments (T1 - coconut fiber; T2 - coconut fiber + goat manure; T3 - goat manure; T4 - goat manure + soil; and T5 - only soil), with four replicates and 32 plants by repetition. At 50 days after sowing, the germination percentage $(\%)$, plant height $(\mathrm{cm})$, number of leaves (unit), stem diameter $(\mathrm{mm})$, fresh mass of the aerial part $\left(\mathrm{g}_{\text {plant }}{ }^{-1}\right)$, total fresh mass $\left(\mathrm{g} \mathrm{plant}^{-1}\right)$, dry mass of the aerial part $\left(\mathrm{g} \mathrm{planta}^{-1}\right)$, total dry mass $\left(\mathrm{g}\right.$ plant $\left.{ }^{-1}\right)$, the percentage of dry mass $(\%)$, and the percentage of root mass in the plant $(\%)$. The results showed that the substrate composed of coconut fiber and goat manure $(1: 1)$, as it provided the best results for the initial development associated with a good percentage of germination, is the most suitable for the production of custard apple seedlings. The soil should be used as a substrate only when associated with some other substrate that increases its porosity, water retention and reduces its mechanical resistance in germination.
\end{abstract}

Keywords: Annona squamosa, seed, dry mass.

\section{INTRODUÇÃO}

A pinha (Annona squamosa, L.), também conhecida como ata ou fruta-doconde, pertence à família das anonáceas, sendo uma espécie de grande expressão econômica no mercado de fruta fresca, com consumo praticamente in natura (DIAS et al., 2003; LEMOS, 2014). No Brasil, a região Nordeste concentra $97 \%$ da produção nacional, sendo o estado da Bahia, com 83\%, o principal produtor, enquanto o Ceará representa $1 \%$ da produção da região (IBGE, 2017).

Nos plantios comerciais, a propagação da espécie é geralmente realizada por via assexuada, na forma de enxertia, sendo os porta-enxertos obtidos via sementes. A reprodução por via sexuada (semente) promove a heterogeneidade das mudas formadas e possui baixa porcentagem de germinação (MENEGAZZO et al., 2012). Segundo Stenzel et al. (2003), as sementes de pinha apresentam substâncias inibidoras da germinação, que, somado ao tegumento resistente e impermeável, proporcionam fatores antagônicos à germinação rápida e uniforme.
O substrato usado na produção de mudas é outro fator que influência na germinação e no desenvolvimento inicial das plantas, tornando-se um fator determinante para o produtor de mudas obter um bom desempenho (BARON et al., 2011). Várias característica e propriedades do substrato podem influenciar a germinação como a estrutura, o pH, a aeração, a capacidade de retenção de água e o grau de contaminação por patógenos, além da disponibilidade de nutrientes, oxigênio, temperatura e luz (SILVA et al., 2014).

Os substratos que possuem esterco caprino em sua composição apresentam um aumento na capacidade de troca cátions, na capacidade de retenção hídrica, na aeração do solo e na agregação do substrato, o que consequentemente reduz os custos de produção, pelo menor uso de adubos químicos e aproveitamento de materiais orgânicos (Ó et al., 2015).

$\begin{array}{rrrr}\text { A escolha } & \text { do } & \text { substrato } & \text { deve } \\ \text { ser feita } & \text { em } & \text { função } & \text { da } \\ \text { disponibilidade, } & \text { do } & \text { custo } & \text { do }\end{array}$
material, da espécie a ser cultivada e das condições de produção (ARAÚJO et al., 2018). Assim, o objetivo deste trabalho foi avaliar a germinação e o desenvolvimento 
inicial da pinha, semeada em diferentes substratos.

\section{MATERIAL E MÉTODO}

O experimento foi conduzido em telado agrícola (sombrite 50\%) pertencente ao Instituto Federal de Educação, Ciência e Tecnologia do Ceará- IFCE/Campus Sobral, no período de outubro a dezembro de 2018. O clima da região, segundo classificação de Köppen é Aw".

As sementes de pinha foram obtidas de frutos maduros adquiridos em feiras do município de Sobral, durante o período de safra. Após a retirada total da polpa, as sementes foram lavadas em água corrente e colocadas para secar a sombra e em seguida armazenadas em ambiente refrigerado até o momento da semeadura.

$\mathrm{O}$ delineamento experimental utilizado foi o inteiramente casualizado (DIC), com cinco tratamentos e quatro repetições, com 32 sementes por repetição. Os tratamentos foram definidos da seguinte forma: T1 - fibra de coco (FC); T2 - fibra de coco + esterco caprino (FC + EC); T3 - esterco caprino (EC); $\mathrm{T} 4$ - esterco caprino + solo $(\mathrm{EC}+\mathrm{S})$; e T5 solo (So).

A formação dos substratos correspondentes aos tratamentos $\mathrm{T} 2$ e $\mathrm{T} 4$ foram obtidos na proporção 1:1 de cada componente. Para a semeadura foram utilizadas bandejas com 128 células, sendo as sementes colocadas a uma profundidade de 1,0 $\mathrm{cm}$. As bandejas foram irrigadas diariamente por um sistema de micro aspersores do tipo microjet com vazão de $15 \quad \mathrm{~L}^{-1}$, com espaçamento de $50 \mathrm{~cm}$ entre eles, com tempo de irrigação de 12 minutos que correspondia uma lâmina de 6,0 mm. Aos 50 dias após a semeadura (DAS), procedeu-se a avaliação do percentual de germinação $(\% \mathrm{G})$ e das variáveis de desenvolvimento: altura das plântulas $(\mathrm{H}, \mathrm{cm})$; número de folhas $(\mathrm{NF}$, und.); diâmetro do caule (DC, mm); massa fresca da parte aérea (MFA, g planta ${ }^{-1}$ ); massa fresca total (MFT, g planta $\left.{ }^{-1}\right)$; massa seca da parte aérea (MAS, g planta $\left.{ }^{-1}\right)$; massa seca total (MST, g planta ${ }^{-1}$ ); porcentagem de massa seca (PMS, \%), obtida segundo a equação 1; e porcentagem da massa da raiz na planta (PR, $\%$ ), obtido de acordo com a equação 2 .

$$
\begin{aligned}
& P M S=\frac{M S T}{M F T} \times 100 \\
& P R=\frac{M S R}{M S T} \times 100
\end{aligned}
$$
planta $^{-1}$

Em que: MSR - massa seca das raízes, g

Com exceção do percentual de germinação, os dados das variáveis de desenvolvimento foram obtidos de oito plântulas. Para a determinação da altura das plantas $(\mathrm{H})$ e do diâmetro do caule (DC) utilizou-se, respectivamente, régua graduada e paquímetro digital.

As massas secas foram obtidas após a secagem do material fresco em estufa de circulação de ar forçado a $65{ }^{\circ} \mathrm{C}$ até que atingissem peso constante. Para a pesagem dos materiais frescos e secos utilizou-se balança analítica com precisão de $\pm 0,001 \mathrm{~g}$.

As variáveis analisadas foram inicialmente submetidas ao teste de normalidade Shapiro-Wilk, apresentando distribuição normal $(P<0,05)$ estes foram submetidos em seguida à análise de variância (ANOVA) pelo teste $\mathrm{F}(P<0,05)$, seguido do teste de comparação de média de Tukey $(P<0,05) \quad$ quando observado efeito significativo. As análises foram realizadas utilizando o software Sisvar 5.7 (FERREIRA, 2019).

\section{RESULTADOS E DISCUSSÃO}

O resumo da análise de variância (ANOVA) das variáveis analisadas submetidas a diferentes substratos estão apresentados na Tabela 1, no qual observa-se que todas as variáveis apresentaram efeito significativo $(P<0,05)$ pelo teste $\mathrm{F}$ para os diferentes tratamentos (substratos) utilizados. 
Tabela 1. Análise de variância (ANOVA) para a altura de plântulas $(\mathrm{H}, \mathrm{cm})$, número de folha (NF, unid.), diâmetro do caule (DC, mm), massa fresca da parte aérea (MFA, g planta ${ }^{-1}$ ), massa fresca total (MFT, g planta $\left.{ }^{-1}\right)$, massa seca da parte aérea (MAS, g planta ${ }^{-1}$ ), massa seca total (MST, g planta ${ }^{1}$ ), porcentagem de massa seca (PMS, \%), porcentagem da massa da raiz na planta (PR, \%) e percentual de germinação $(\% \mathrm{G})$ em função de diferentes substratos no desenvolvimento inicial de mudas de pinha.

\begin{tabular}{|c|c|c|c|c|c|c|}
\hline \multirow{2}{*}{ Fonte de Variação } & \multirow{2}{*}{ GL } & \multicolumn{5}{|c|}{ Quadrado Médio } \\
\hline & & $\mathrm{H}$ & $\mathrm{NF}$ & $\mathrm{DC}$ & MFA & MFT \\
\hline Tratamento & 4 & $7,560^{* * * *}$ & $2,265^{* * *}$ & $0,043^{*}$ & $5,232^{* * *}$ & $7,387^{* * * *}$ \\
\hline Erro & 15 & 0,442 & 0,162 & 0,013 & 0,339 & 0,396 \\
\hline $\mathrm{CV}(\%)$ & & 7,49 & 10,78 & 3,94 & 13,68 & 11,56 \\
\hline Média & & 8,88 & 3,72 & 2,89 & 4,26 & 5,45 \\
\hline \multirow{2}{*}{ Fonte de Variação } & \multirow{2}{*}{ GL } & \multicolumn{5}{|c|}{ Quadrado Médio } \\
\hline & & MSA & MST & PMS & PR & $\% \mathrm{G}$ \\
\hline Tratamento & 4 & $0,247^{* * *}$ & $0,313^{* * *}$ & $6,525^{* *}$ & $47,984^{* * *}$ & $1968,5^{* * *}$ \\
\hline Erro & 15 & 0,015 & 0,02 & 0,801 & 2,746 & 49,6 \\
\hline $\mathrm{CV}(\%)$ & & 14,43 & 13,28 & 4,64 & 8,15 & 14,88 \\
\hline Média & & 0,85 & 1,06 & 19,28 & 20,32 & 47,35 \\
\hline
\end{tabular}

Nota: *,**,*** - Significativos a 5\%, $1 \%$ e $0,1 \%$ de significância pelo teste de F, respectivamente. GL - grau de liberdade; CV - coeficiente de variação.

O efeito significativo observado $(P<0,05)$ em todas as variáveis analisadas demonstra que a escolha do substrato tem grande importância no desenvolvimento das plântulas de pinha, sendo fator determinante na produção de mudas, como relata Baron et al. (2011). Observou-se que os substratos T2 $(\mathrm{FC}+\mathrm{EC})$ e $\mathrm{T} 5$ (So) não diferiram estatisticamente $(P<0,05)$ para a variável percentual de germinação $(\% \mathrm{G})$, apresentando médias de $69 \%$ e $74 \%$ respectivamente (Figura 1). No entanto, a germinação no solo apresentou um retardo maior que os demais tratamentos, semelhante ao observado por Costa et al. (2019). Esse retardo pode ser explicado pelo trabalho de Periotto e Gualtieri (2017), avaliando o desempenho de quatro diferentes substratos (vermiculita, fibra de coco/vermiculita $2: 1$, areia fina e fibra de coco) na emergência e no desenvolvimento inicial de plântulas e mudas de Campomanesia pubescens. Os autores op cit. verificaram menor percentual de germinação em areia fina, sendo que o principal fator negativo é a resistência mecânica desse tipo de substrato em relação aos demais substratos. 


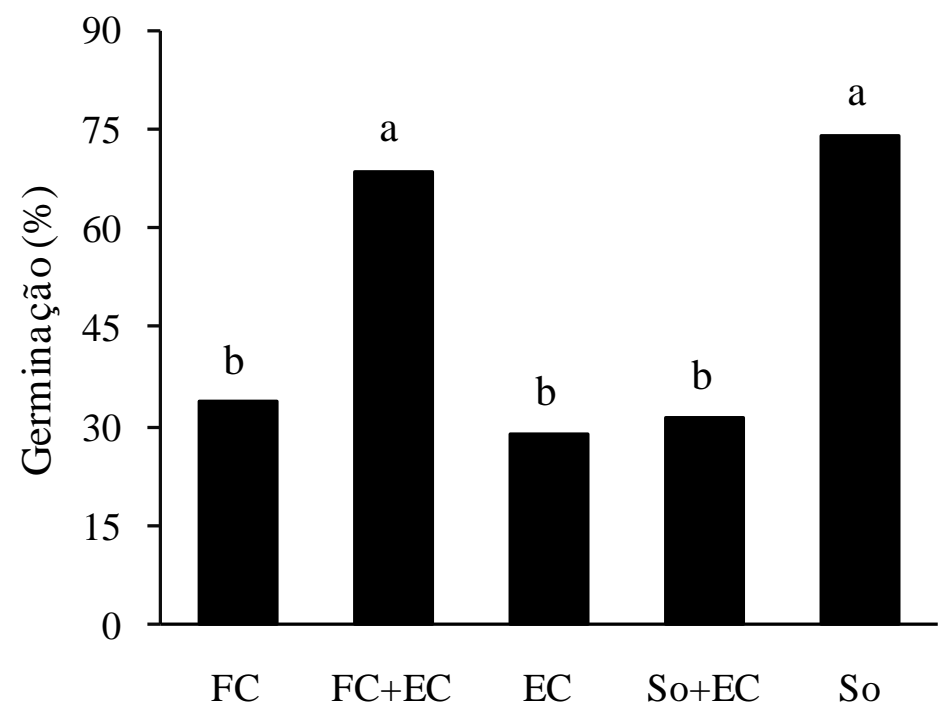

*médias seguidas pela mesma letra não diferem entre si pelo teste de Tukey $(\mathrm{P}<0,05)$

Figura 1. Percentual de germinação de plântulas de pinha em diferentes substratos aos 50 DAS. T1 - fibra de coco (FC); T2 - fibra de coco + esterco caprino (FC + EC); T3 - esterco caprino (EC); T4 - esterco caprino + solo (EC + S); e T5 - solo (So).

Cavalcante et al. (2016) observaram que a adição de composto orgânico ao solo melhora significativamente as condições de germinação e desenvolvimento inicial das mudas de gliricídias (Gliricídia sepium) em relação a utilização do solo apenas.

O trabalho de Araújo et al. (2018) corrobora com esses resultados, os autores observaram que o substrato formado por solo e esterco caprino na proporção 1:1, proporcionou um aspecto mais vigoroso das plantas de rúcula (Eruca sativa L.). Porém, esse tratamento apresentou baixo percentual de germinação $(\mathrm{G}=31 \%)$, que para situações com pouco material de propagação deixa de ser atrativo para sua utilização. Os melhores resultados do tratamento $\mathrm{T} 2$ (FC+EC), possivelmente, estão relacionados com as características físico e química do substrato, que em função dos materiais utilizados apresentam alta porosidade, boa retenção de água e disponibilidade de nutrientes. Tais características são consideradas essenciais para a escolha de um substrato (CUNHA et al., 2006; CALDEIRA et al., 2012; GOMES et al., 2015; MARQUES et al., 2018).

Analisando as variáveis altura, número de folhas e diâmetro do caule (Figura 2), observa-se que o melhor desempenho foi obtido com o tratamento T2 (FC+EC) em relação aos demais, embora este tenha diferido significativamente $(P>0,05)$ apenas em relação ao T5 quanto a variável número de folhas (Figura 2B). O tratamento T2 apresentou altura média das plântulas de 10,95 $\mathrm{cm}, 35 \%$ superior à média observada em $\mathrm{T} 5$ (So), com 7,13 cm (Figura 2A). Quanto ao diâmetro do caule (Figura 2C), apenas o tratamento T5 diferiu significativamente $(P<0,05)$ do tratamento $\mathrm{T} 2(\mathrm{FC}+\mathrm{EC})$. 

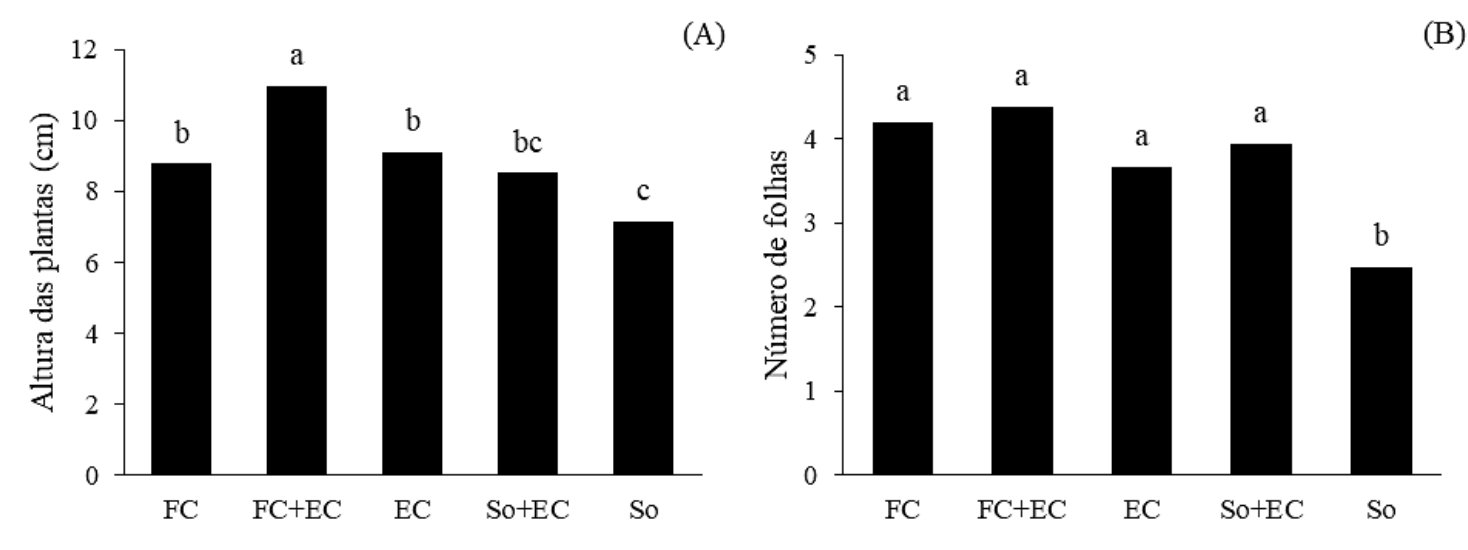

(C)

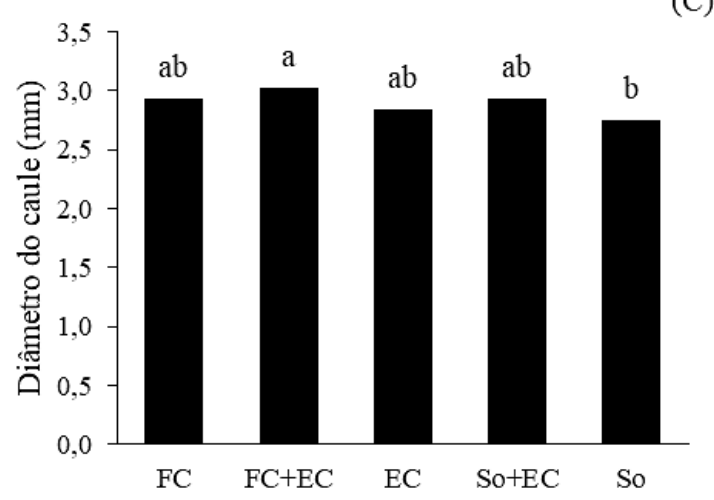

*médias seguidas pela mesma letra não diferem entre si pelo teste de Tukey $(P<0,05)$

Figura 2. Médias da altura das plântulas - H (A), número de folhas - NF (B) e diâmetro do caule - DC (C) de plântulas de pinha obtidas em função de diferentes substratos aos 50 DAS. T1 - fibra de coco (FC); T2 - fibra de coco + esterco caprino (FC + EC); T3 - esterco caprino (EC); T4 - esterco caprino + solo (EC + S); e T5 - solo (So).

Entre as variáveis apresentadas na Figura 2 a altura das plântulas foi a mais influenciada pelo tratamento aplicado. Ó et al. (2015) destacam que o melhor desempenho do esterco caprino se deve ao fato deste apresentar fermentação mais rápida, ou seja, menor tempo de decomposição que favorece a liberação mais rápida dos nutrientes paras as plântulas. Esse resultado corrobora com o comentado por Mexal e Lands (1990), ao relatarem que a altura da planta apresenta uma boa estimativa do crescimento inicial da muda no campo, sendo aceita como uma boa medida do potencial de desempenho da planta.

As variáveis não destrutivas apresentadas são essenciais na determinação visual da qualidade das mudas, contudo estas devem ser avaliadas sempre que possível de forma combinada com outras características, como massa fresca e seca, visando expressar os resultados com precisão, (GOMES et al., 2002). Assim, na Figura 3 estão apresentados os resultados médios da massa fresca e seca da parte área e total das mudas de pinha. A massa fresca da parte aérea (MFA) apresentou média de $4,26 \mathrm{~g} \mathrm{planta}^{-1}$ variando de 5,70 a $2,49 \mathrm{~g}$ planta $^{-1}$ para os tratamentos T2 e T5, respectivamente, tendo o mesmo comportamento para massa fresca total (Figura 3A). Com relação a massa seca da parte aérea (MSA) e massa seca total (MST) apresentaram média de 0,85 e $1,06 \mathrm{~g}_{\text {planta }}{ }^{-1}$, tendo como destaque para os maiores valores obtidos pelo tratamento T2 com média de 1,09 e 1,32 g planta $^{-1}$, respectivamente para MAS e MST, embora este não tenha diferido significativamente $(P>0,05)$ dos tratamentos T1, T3 e $\quad$ T4 (Figura 3B). 

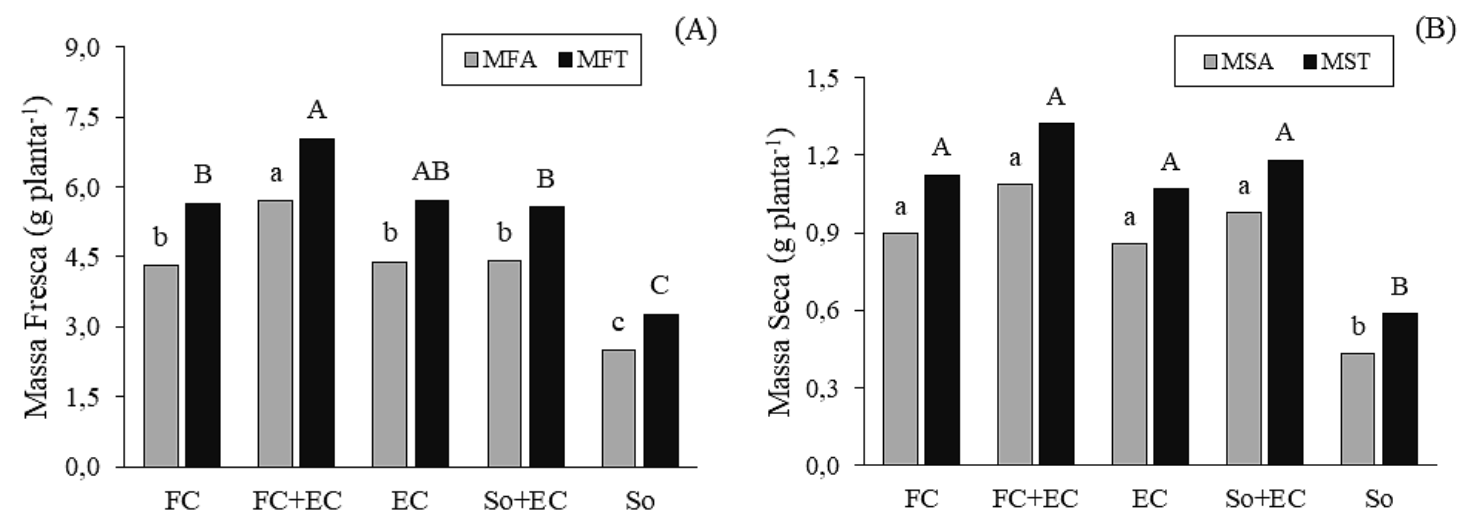

*médias seguidas de mesma letra minúsculas não diferem entre si pelo teste de Tukey $(\mathrm{P}<0,05)$ para as variáveis MFA e MSA; **médias seguidas de mesma letra maiúscula não diferem entre si pelo teste de Tukey $(\mathrm{P}<0,05)$ para as variáveis MFT e MST.

Figura 3. (A) Massa fresca aérea (MFA) e massa fresca total (MFT); e, (B) massa seca aérea (MSA) e massa seca total (MST) de plântulas de pinha obtidas em função de diferentes substratos aos 50 DAS. T1 - fibra de coco (FC); T2 - fibra de coco + esterco caprino (FC + EC); T3 - esterco caprino (EC); T4 - esterco caprino + solo (EC + S); e T5 - solo (So).

A massa seca da parte aérea (MSA) é apontada como um indicador do grau de rusticidade das mudas, sendo que quanto maior for seu valor, mais rústica a muda será, pois, as mudas devem estar endurecidas no momento do plantio (GOMES; PAIVA NETO, 2004). Dessa forma, haverá maior resistência às condições adversas do campo, o que promove maior sobrevivência e minimiza gastos com replantios (CALDEIRA et al., 2014; MARQUES et al., 2018). Assim, apenas o tratamento T5 apresentou desempenho significativamente $(P<0,05)$ abaixo dos demais tratamentos para todas as variáveis de massa fresca e seca (Figura 3).

Na Figura 4 estão apresentados os dados do percentual de massa seca (PMS) e o percentual de massa da raiz na planta (PR) para as mudas de pinha em diferentes substratos. Observa-se que o tratamento T5 apresenta menor PMS $(17,90 \%)$ e maior PR $(26,15 \%)$, no qual este último diferiu significativamente $(P<0,05)$ de todos os demais tratamentos.

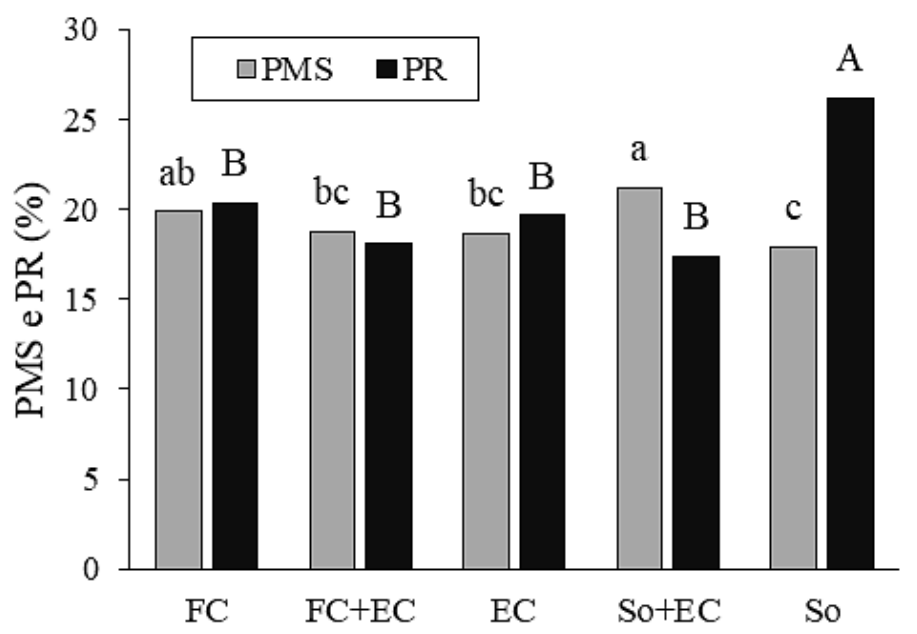

*médias seguidas de mesma letra minúsculas não diferem entre si pelo teste de Tukey $(\mathrm{P}<0,05)$ para a variável PMS;

**médias seguidas de mesma letra maiúscula não diferem entre si pelo teste de Tukey $(\mathrm{P}<0,05)$ para as variáveis $\mathrm{PR}$.

Figura 4. Médias da porcentagem de massa seca (PMS) e da porcentagem de massa da raiz na planta (PR) em mudas de pinha obtidas em função de diferentes substratos. T1 - fibra de coco (FC); T2 - fibra de coco + esterco caprino (FC + EC); T3 - esterco caprino (EC); T4 - esterco caprino + solo (EC + S); e T5 - solo (So). 
A porcentagem de matéria seca (PMS) ou teor de matéria seca, representa uma estimativa da quantidade de água e de matéria sólida que a planta utiliza durante seu desenvolvimento para a formação de seus tecidos (ALVARENGA, 1999; BOAS et al., 2007; COSTA, 2019). A maior percentagem de raiz (PR) e o menor porcentagem de massa seca (PMS) corrobora com o menor desempenho das demais variáveis analisadas para o tratamento T5. O substrato formado apenas por solo limitou o desenvolvimento das mudas por proporcionar menor retenção de água, maior resistência a penetração de raiz e menor aeração, que acaba por fazer a muda investir mais nas raízes do que na parte aérea (CAVALCANTE et al., 2016).

O melhor desempenho geral, tanto do ponto de vista da germinação quanto do desenvolvimento das mudas, é observado no tratamento com substrato composto por fibra de coco mais esterco caprino (T2), pois apresentou, em geral, desempenho significativamente $(P<0,05)$ melhor quanto às variáveis de crescimento das mudas, além de apresentar boa porcentagem de germinação com 69\% (Figura 1). Esse resultado deve-se, possivelmente, por esse substrato (T4) associar características que proporcionam melhores condições de germinação e desenvolvimento das mudas. Esse resultado corrobora com os observados por Carrijo et al. (2002) e Periotto e Gualtieri (2017), ao relatarem que a fibra de coco apresenta bons resultados quando associado a outros substratos que suprem suas carências principalmente nutritivas. Contudo, Cavalcante et al. (2016) obtiveram bons resultados de germinação e qualidade das mudas quando da utilização de solo associado a composto orgânico na proporção de $2: 1$.

\section{CONCLUSÕES}

O substrato composto por fibra de coco e esterco caprino (1:1), é o mais indicado para a produção de mudas de pinha por proporcionar melhor desenvolvimento inicial associado à melhor percentagem de germinação.

O substrato composto apenas por solo retarda a germinação das plântulas e proporciona menor desempenho para o desenvolvimento inicial de mudas de pinha, sendo recomendado seu uso com outros materiais.

\section{REFERÊNCIAS BIBLIOGRÁFICAS}

ALVARENGA, M. A. R. Crescimento, teor e acúmulo de nutrientes em alface americana (Lactuca sativa L.) sob doses de nitrogênio aplicadas no solo e de níveis de cálcio aplicados via foliar. Tese de Doutorado. Universidade Federal de Lavras, Lavras: UFLA, 117 p. 1999.

ARAÚJO, B. DE A.; DEMONTIÊZO, F. L. L.; ARAÚJO, D. A.; SILVA, E. S.; VALNIR JÚNIOR, M.; MOREIRA, F. J. C. Desenvolvimento de Eruca sativa L. sob diferentes lâminas de irrigação e substratos. Revista Brasileira de Agricultura Irrigada, v. 12, n. 4, p. 2731-2739, 2018.

BARON, D.; FERREIRA, G.; BOARO, C. S. F.; MISCHAN, M. M. Evalution of substrates on the emergence of "araticum-de-terra-fria" (Annona emarginata (Schltdl.) H. Rainer) seedlings. Revista Brasileira de Fruticultura, v. 33, n. 2, p. 575-586, 2011.

BOAS, R. C. V.; CARVALHO, J. A.; GOMES, L. A. A.; SOUZA, K. J.; RODRIGUES, R. C.; SOUSA, A. M. G. Efeito da irrigação no desenvolvimento da alface crespa, em ambiente protegido, em lavras, MG. Revista Brasileira de Engenharia Agrícola e Ambiental, v. 11, n. 4, p. 393-397, 2007.

BRASIL - Instituto Nacional de Meteorologia - INMET. Banco de dados meteorológicos para ensino e pesquisa - BDMEP. Estação meteorológica de Sobral, CE. Disponível em: 
$<$ http://www.inmet.gov.br/portal/index.php?r= bdmep/bdmep>. Acesso: 25 nov. 2018.

CALDEIRA, M. V. W.; PERONI, L.; GOMES, D. R.; DELARMELINA, W. M.; TRAZZI, P. A. Diferentes proporções de biossólido na composição de substratos para a produção de mudas de timbó (Ateleia glazioveana Baill). Scientia Florestais, v. 40, n. 9, p. 15-22, 2012.

CARNEIRO, J. G. de A. Produção e controle de qualidade de mudas florestais. Curitiba: UFPR; 1995. $451 \mathrm{p}$.

CARRIJO, O. A.; LIZ, R. S.; MAKISHIMA, $\mathrm{N}$. Fiber of green coconut shell as an agricultural substrate. Horticultura Brasileira [online]. v.20, n.4, p.533-535, 2002.

CAVALCANTE, A. C. P.; SILVA, A. G.; SILVA, M. J. R.; ARAÚJO, R. C. Produção de mudas de gliricídia com diferentes substratos orgânicos. Revista Agrarian, v. 9, n. 33, p. 233-240, 2016.

CORDEIRO, M. C. R.; PINTO, A. C. DE Q.; RAMOS, V. H. V. O cultivo da pinha, frutado-conde ou ata no Brasil. Brasília: Embrapa Cerrados, 2000. 52 p. (Circular Técnica, 9).

COSTA, J. N. Desempenho de quatro variedades de alface sob diferentes lâminas de irrigação e proteção ambiental. Monografia (Graduação em Tecnologia em Irrigação e Drenagem). Instituto Federal de Educação, Ciência e Tecnologia IFCE/Campus Sobral - CE, 58 p. 2019.

COSTA, J. N.; OLIVEIRA FILHO, P.; ALMEIDA, C. L.; LIMA, J. S.; SILVA, D. M. Germinação da pinha em diferentes substratos. In: SIMPÓSIO BRASILEIRO DE RECURSOS NATURAIS DO SEMIÁRIDO, 4., 2019, Crato. Anais eletrônicos... Crato: SBRNS, 2019. Disponível em: <https://sbrns2019.blogspot.com/p/anais-doiv-sbrns-2019.html>.Acesso em: 15 abr. 2020.
CUNHA, A. de M.; CUNHA, G. de M.; SARMENTO R. de A.; CUNHA, G. de M.; AMARAL, J. F. T do. Efeito de diferentes substratos sobre o desenvolvimento de mudas de Acacia sp. Revista Árvore, v.30, n.2, p. 207-214, 2006.

DIAS, N. O.; MATSUMOTO, S. N.; REBOUÇAS, T. N. H.; VIANA, A. E. S.; SÃO JOSÉ, A. R.; SOUZA, I. V. B. Influência da poda de produção em ramos de diferentes diâmetros no desenvolvimento vegetativo e reprodutivo da pinheira (Annona squamosa L.). Revista Brasileira de Fruticultura, v. 25, n. 1, p. 100-103, 2003.

FERREIRA, T. T. S.; RODRIGUES, D. N. B.; GOMES FILHO, R. R. Demanda hídrica de fruteiras utilizando coeficiente de redução da evapotranspiração adequado a região do baixo jaguaribe no Ceará. Revista Brasileira de Agricultura Irrigada, v. 4, n. 4, p. 217-225, 2010.

FERREIRA, D. F. Sisvar: a computer analysis system to fixed effects Split plot type designs. Revista Brasileira de Biometria, v.37, n.4, p.529-535, 2019.

GOMES, J. M.; COUTO, L.; LEITE, H. G.; XAVIER, A.; GARCIA, S. L. R. Parâmetros morfológicos na avaliação da qualidade de mudas de Eucalyptus grandis. Revista Árvore, v. 26, n. 6, p. 655-664, 2002.

GOMES, J. M.; PAIVA NETO. H. de; Viveiros florestais: propagação sexuada. Viçosa: UFV; 2004. 116 p.

GOMES, J. P.; OLIVEIRA, L. M.; FRANÇA, C. S. S.; DACOREGIO, H. M.; BORTOLUZZI, R.; C. Caracterização morfológica de plântulas durante a germinação de sementes de Psidium cattleianum e Acca sellowiana (Myrtaceae). Ciência Florestal, v. 25, n. 4, p. 1035-1042, 2015.

IBGE - Instituto Brasileiro de Geografia e Estatística. Censo agropecuário de 2017. Disponível em: 
https://www.ibge.gov.br/estatisticasnovoportal/economicas/ agricultura-e-pecuaria/21814-2017-censoagropecuario. $h t m l ?=\& \mathrm{t}=$ resultados $>$ Acesso: 10 jan. 2019.

LEMOS, E. E. P. A produção de anonáceas no Brasil. Revista Brasileira de Fruticultura, v. 36, n.esp. 1 p. 77-85, 2014.

MARQUES, A. R. F.; OLIVEIRA, V. S.; BOLIGON, A. A.; VESTENA, S. Produção e qualidade de mudas de Psidium cattleianum var. cattleianum Sabine (Myrtaceae) em diferentes substratos. Acta Biológica Catarinense, v. 5, n. 1, p. 5-13, 2018.

MENEGAZZO, M. L.; OLIVEIRA, A. C.; KULCZYNSKI, S. M.; SILVA, E. A. da. Efeitos de métodos de superação de dormência em sementes de pinha (Annona squamosa L.). Revista Agrarian, v. 5, n. 15, p. 29-35, 2012.

MEXAL, J. L.; LANDS, T. D. Target seedling concepts: height and diameter. In: TARGET SEEDLING SYMPOSIUM, MEETING OF THE WESTERN FOREST NURSERY ASSOCIATIONS, GENERAL TECHNICAL REPORT RM- 200, 1990, Roseburg. Proceedings. Fort Collins: USDA, Forest Service, 1990. p. 17-35.

Ó, K. D. S.; SILVA, G. H.; SANTOS, R. V. Crescimento inicial de angico em substratos com co-produtos de mineração e matéria orgânica. Revista Verde, v. 10, n. 1, p. 178 186, 2015.

PERIOTTO, F.; GUALTIERI, S. C. J.
Germinação e desenvolvimento inicial de Campomanesia pubescens (dc.) o. Berg (Myrtaceae) em diferentes substratos. Ciência Florestal, v. 27, n. 3, p. 743-752, 2017.

PINHO, B. M. Uso de diferentes substratos para a produção de mudas de cajueiro (Anacardium occidentale L.). Monografia (Graduação em Agronomia). Universidade Federal do Ceará - UFC, Fortaleza - CE, 43 p. 2018.

RIBEIRO, C. S.; OLIVEIRA, A. C.; SILVA, V. L.; FRANÇA, S. C.; SILVA, R. V. FONSECA, J. F.; SILVA, T. I. Produção de mudas de Passiflora edulis sob diferentes substratos orgânicos. Colloquium Agrariae, v. 14, n. 3, p. 104-112, 2018.

SILVA, V. F.; BRITO, K. S. A.; NASCIMENTO, E. C. S.; ANDRADE, L. O.; FERREIRA, A. C. Efeito de diferentes substratos na germinação de genótipos de girassol. Revista Verde v. 9, n. 4, p. 16 - 20, 2014.

SILVA, V. L.; OLIVEIRA, A. C.; SILVA, W. V.; SANTOS, R. O.; JARDIM, C. C. S. Características morfológicas de mudas de pinheira (Annona squamosa L.) submetidas a diferentes substratos e doses de boro. Cultura Agronômica, v. 27, n. 1, p. 67-77, 2018.

STENZEL, N. M. C.; MURATA, I. M.; NEVES, C. S. V. Superação da dormência em sementes de atemóia e fruta-do-conde. Revista Brasileira de Fruticultura, v. 25, n. 2, p. 305-308, 2003. 